Resenha por: Marcelo Dayrell Vivas ${ }^{1}$

\title{
DERECHO Y SALUD COMO REALIDADES INTERACTIVAS
}

Jorge Tomillo Urbina e Joaquín Cayón de Las

Cuevas (Coord.), Aranzadi, Espanha, 2015

${ }^{1}$ Defensoria Pública do Estado de São Paulo. São Paulo/SP, Brasil.

Correspondência: Marcelo Dayrell Vivas. E-mail: marcelodayrell@gmail.com.

Recebido em: 09/12/2015. 
A publicação Derecho y Salud como Realidades Interactivas é uma coletânea de 60 artigos escritos por expositores dos IV, V e VI Encontros Interautonômicos sobre Proteção Jurídica do Paciente como Consumidor, realizados respectivamente nos anos de 2011, 2012 e 2013 em Cantábria, comunidade autônoma da Espanha. Trata-se de obra fundamental aos interessados nos debates atuais do direito sanitário no contexto espanhol, promovendo diálogo entre acadêmicos e gestores nas áreas do direito e da saúde.

A obra é organizada em 12 blocos, sendo o primeiro constituído pela introdução e os demais organizados segundo os temas principais dos artigos. Considerando a limitação da presente resenha, focarei em apenas um ou dois artigos de cada bloco de acordo com o que julgo relevante na temática do direito sanitário.

O primeiro capítulo da obra, escrito pelos organizadores Jorge Tomillo Urbina e Joaquín Cayón de Las Cuevas, visa a esclarecer a dinâmica e os objetivos dos Encontros Interautonômicos, bem como as razões subjacentes à seleção e à compilação dos artigos para a composição da obra que ora se apresenta. Esse capítulo traz o histórico da relação entre direito e saúde, ou entre juristas e médicos, desde a época medieval, culminando na substituição do modelo sanitário tradicional por um modelo de serviço público constitucionalizado, construído com base na garantia de direitos fundamentais, na autonomia do paciente e na paridade de posições que deve guiar a relação entre médico e paciente. Os autores apontam que se trata de uma área essencialmente interdisciplinar e que a atuação cooperativa e colaborativa favorece a solução de problemas da saúde.

O segundo bloco trata da epistemologia e sociologia jurídica dos sistemas de saúde. Nele se destaca o artigo de Maria Célia Delduque, que apresenta uma distinção entre o direito sanitário e o direito médico. Em minha perspectiva, essa diferenciação, com a conceituação de direito sanitário, mostra-se importante para uma correta delimitação da disciplina, entendendo-a como detentora de problema próprio e métodos autônomos de investigação, ainda que com intensa correlação e diálogo com outras disciplinas e com outros ramos do direito ${ }^{1,2}$.

Os trabalhos apresentados por Susana López Altuna e Fernando González Ausín e por Eduardo Vázquez de Castro tratam especificamente da história clínica sob a óptica nacional espanhola e específica do país basco, estando inseridos no terceiro bloco, sobre consentimento informado e documentação clínica. Altuna e Ausín discorrem sobre o acesso às "anotações subjetivas", que são as impressões ou valorações pessoais dos profissionais sanitários não sustentadas em dados ou provas complementares e que podem interessar para a assistência ao paciente. Na legislação

\footnotetext{
${ }^{1}$ DALLARI, S. Uma nova disciplina: o direito sanitário. Rev. Saúde Públ., v. 22, n. 2, p. 327-334, 1988. Disponível em: <http://www.scielo.br/pdf/rsp/v22n4/08.pdf>. http://dx.doi.org/10.1590/S0034-89101988000400008. ${ }^{2}$ AITH, F. Curso de direito sanitário: a proteção da saúde no Brasil. São Paulo: Quartier Latin, 2007.
} 
basca, constitui direito do profissional a reserva às anotações subjetivas, as quais não precisam ser fornecidas ao paciente quando este busca acesso ao próprio prontuário. Castro explicita os direitos do paciente em relação à informação e documentação clínica, inclusive com a aplicação da legislação específica sobre banco de dados no caso da história clínica eletrônica. Contudo, creio que resta sem solução a discussão acerca do que constituem "anotações subjetivas" para o fim de limitar seu acesso e em que medida a história clínica é propriedade do paciente ou produção intelectual da equipe que o atendeu. Os autores não fazem qualquer referência à legislação comparada, o que seria pertinente - considerando-se que no Brasil, por exemplo, a requisição de cópias de prontuários pelo Poder Judiciário ainda é um tema bastante controverso e contraditório nas relações estabelecidas entre os serviços de saúde e os órgãos do sistema de justiça.

O quarto bloco refere-se aos contratos privados de assistência sanitária, e os dois artigos que nele estão inseridos tratam da responsabilidade da seguradora por erros ou negligências dos prestadores de serviços a ela vinculados. Tanto o artigo de Jorge Tomillo Urbina quanto o trabalho de Vicente Gonzalo López trabalham com os entendimentos jurisprudenciais atuais e destacam a distinção entre o "seguro de assistência sanitária" e o "seguro de enfermidades" (em tradução livre). O seguro de enfermidades refere-se unicamente ao reembolso de gastos médicos e farmacêuticos, enquanto o seguro de assistência sanitária é aquele em que a seguradora coloca os meios à disposição do paciente. Trazendo a temática para o caso brasileiro, observa-se que a discussão sobre judicialização da saúde suplementar no país tem se notabilizado pela maior proximidade com o direito do consumidor em relação à própria legislação que regulamenta os planos de saúde ${ }^{3}$, o que condiz com os debates realizados nos Encontros sobre o paciente na condição de consumidor.

O quinto bloco apresenta-se como tratando da saúde e assistência sanitária no início da vida, sendo que seus dois primeiros artigos focam, respectivamente, o estatuto jurídico do embrião humano e o diagnóstico pré-implantacional, áreas bastante polêmicas concernentes à bioética e ao biodireito. Jimena Beatriz Manjón Rodríguez apresenta o debate sobre a existência (ou não) de um direito ao parto por cesárea, considerando que é evidente o crescimento das taxas de parto por cesárea na Espanha e no mundo, em especial nos hospitais privados, e que esse tipo de parto é muitas vezes demandado pelas parturientes com base em fatores extraclínicos. Chama à atenção que recente regulamentação realizada no âmbito do Ministério da Saúde no Brasil (Portaria MS/SAS n. 371/2014 e Resolução Normativa ANS n. 368/2015) gerou bastante polêmica sobre eventual obrigatoriedade ou preferência dos partos ditos normais (vaginais). Curioso que os movimentos feministas, pelo

\footnotetext{
${ }^{3}$ SCHEFFER, M. Coberturas assistenciais negadas pelos planos e seguros de saúde em ações julgadas pelo Tribunal de Justiça do Estado de São Paulo. Revista de Direito Sanitário, São Paulo, v. 14, n. 1, p. 122-132, mar./jun. 2013. Disponível em: <http://www.revistas.usp.br/rdisan/article/view/56627>. http://dx.doi.org/10.11606/issn.2316-9044.v14i1p122-131.
} 
menos no Brasil, têm centrado forças em defender o direito da mulher ao parto normal, mas não se realiza uma discussão, no âmbito de tais movimentos, acerca do direito da mulher ao parto por cesárea, como propõe Rodríguez.

A atenção farmacêutica é a temática do sexto bloco, em que se destaca o trabalho de Gustavo Merino Gómez sobre as doenças raras e os medicamentos órfãos. $\mathrm{O}$ autor critica que, em regra, são lançadas estratégias, programas e/ou iniciativas, mas sem uma regulamentação normativa sobre a matéria. Compete-me apontar que esse tema ainda demanda maior desenvolvimento no âmbito do direito sanitário, sendo que o Brasil recentemente criou uma política nacional por meio do Ministério da Saúde (Portaria MS n. 199/2014).

O sétimo bloco é apresentado sob o título de "saúde pública". Nele, Javier García Amez apresenta primoroso trabalho sobre os direitos e deveres no campo da saúde pública, seguido por outros diversos artigos tratando do Observatório de Saúde Pública de Cantábria e de projetos realizados em seu âmbito. Amez especifica o quadro legislativo espanhol no âmbito sanitário e detalha diversos direitos e deveres do usuário, dentre os quais chamam atenção os tratamentos sanitários involuntários. Vale apontar, contudo, que, pelo menos na forma apresentada no artigo, não há qualquer correlação entre a necessidade de tratamentos forçados e o sistema de vigilância em saúde pública, o qual é tratado separadamente. Essa situação também ainda se verifica no Brasil, motivo pelo qual autores como Aith e Dallari ${ }^{4}$ discutem os riscos sanitários nos anos atuais e a necessidade de criação de um sistema nacional de vigilância em saúde que possa orientar ações emergenciais, incluindo tratamentos involuntários.

A atenção sociossanitária é abordada em quatro artigos do bloco oitavo, tratando da interseção entre o sistema sanitário e o sistema de assistência social. Carmen Martín Núñez define espaço sociossanitário, coordenação sociossanitária e atenção sociossanitária, trazendo, em seguida, a regulamentação legal sobre coesão e qualidade do sistema nacional de saúde espanhol. O trabalho ainda apresenta os desafios da atenção sociossanitária e algumas propostas de solução. Cabe aqui destacar que, no caso brasileiro, a constituição do Sistema Único de Assistência Social (SUAS) enquanto uma política pública, consolidada na última década, ainda traz como desafio exatamente a atenção às pessoas que demandam intervenções de políticas sociais e de políticas sanitárias - havendo, em alguns casos, uma sobreposição de ações e, em muitos outros, uma ausência de atendimento. A experiência espanhola, até mesmo com suas limitações e dificuldades, pode certamente contribuir para um maior diálogo e interação entre os serviços constituintes do Sistema Único de Saúde (SUS) e do SUAS.

\footnotetext{
${ }^{4}$ AITH, F.; DALLARI, S. Vigilância em saúde no Brasil: os desafios dos riscos sanitários do século XXI e a necessidade de criação de um sistema nacional de vigilância em saúde. Revista de Direito Sanitário, São Paulo, v. 10, n. 2, p. 94-125, ago./nov. 2009. Disponível em: <http://www.revistas.usp.br/rdisan/article/ view/13165>. http://dx.doi.org/10.11606/issn.2316-9044.v10i2p94-125.
} 
O nono bloco traz, sob o título de "pessoas da saúde", uma discussão sobre aposentadoria e medidas de recursos humanos. Maria Cruz Reguera Andrés discute a feminização da medicina, a partir de índices de maior participação da mulher em cursos da área de saúde e sua atuação como profissionais do sistema nacional de saúde. $\mathrm{O}$ artigo centra-se na desnecessidade de alguma medida afirmativa para possibilitar uma maior participação masculina na área da saúde, pois não há qualquer tipo de obstáculo. Se as mulheres são mais qualificadas e competentes, podem, portanto, prestar um atendimento de melhor qualidade. Contudo, percebo que essa argumentação coloca em xeque os fundamentos de ações afirmativas para mulheres em outros âmbitos, que se fundamenta na ideia de pluralidade e diversidade humana.

Diversas questões setoriais são reunidas no décimo bloco, podendo-se destacar os trabalhos de Maria Paz Pous de La Flor e de Joaquín Cayón de Las Cuevas, María Elena Balmori Gómez e Guillermina Navarro Caballero sobre o transplante de órgãos. La Flor apresenta a regulamentação sobre o tema e a discussão existente na União Europeia, apontando os desafios do tráfico de órgãos, da (in)disponibilidade de órgãos e da (necessidade de) doação em vida, trazendo, ainda, as diferenças entre doação de órgãos por pessoas vivas e a doação de órgãos de pessoas falecidas. Las Cuevas, Gómez e Caballero discutem especificamente a proibição de comércio de órgãos para transplantes nas perspectivas internacional e espanhola. Os dois trabalhos trazem, ainda, a discussão sobre a consulta à família acerca da doação de órgãos da pessoa falecida, o que - vale salientar - já foi objeto de seguidas alterações normativas no Brasil. A discussão consiste em saber se é legítimo buscar um maior número de órgãos para transplante por meio da obediência à autorização legal de retirada de órgãos de pessoa falecida, desde que não haja oposição em vida, banindo-se a prática da consulta às famílias.

O décimo primeiro bloco trata da segurança do paciente e da qualidade assistencial, abordando, em muitos trabalhos, a publicação "Errar é Humano", lançada em 2000 pelo Instituto de Medicina dos Estados Unidos. Fuensanta Muñoz Saco apresenta o sistema de notificação e registro de incidentes e eventos adversos na Espanha, assim como os atuais desafios, como a não obrigatoriedade de adesão das comunidades autônomas, a relação com o sistema de justiça (sigilo e implicações legais) e a falta de clareza quanto ao responsável, à facultatividade, à abrangência e ao caráter confidencial e anônimo da notificação. Tais desafios, a meu ver, dizem respeito à própria efetividade da implementação de um sistema público de notificações e de prevenção de incidentes e eventos adversos.

Finalmente, o décimo segundo bloco trata de outros sistemas ibero-americanos de saúde, destacando-se o trabalho de Fernando Rovira Villademoros, que aborda a participação social no sistema nacional integrado de saúde do Uruguai. O sistema de saúde naquele país foi implantado por uma reforma em 2007, com a proposta de garantir o acesso universal a serviços integrais de saúde, guiados pelos princípios da equidade, da continuidade e da oportunidade. $\mathrm{O}$ autor apresenta 
quatro espaços de participação: conselhos consultivos e assessores dos prestadores; comissão de bioética e qualidade integral de atenção à saúde, junto ao Ministério da Saúde; Junta Nacional de Saúde, que administra os recursos da saúde; e diretório da Administração de Serviços de Saúde do Estado (ASSE), que é responsável pela execução dos serviços estatais de saúde. Observo que os desafios apresentados são bastante semelhantes àqueles encontrados nos espaços de democracia participativa no Brasil, como a atual conformação quanto a composição, formato, poder decisório $\mathrm{e}$ às próprias assimetrias verificadas $\mathrm{s}^{5,6}$.

A obra busca trazer um olhar sobre o paciente na condição de consumidor e, por essa razão, aborda, em muitos artigos, questões relacionadas à responsabilidade civil, ao custeio do sistema sanitário e aos recursos humanos em saúde. Colocar o usuário dos serviços de saúde enquanto consumidor pode ser uma importante estratégia de proteção, trazendo um novo marco normativo para a garantia de direitos ${ }^{7}$. Contudo, deve-se atentar à saúde como direito e ao serviço de saúde como política, evitando sua mera mercantilização, recordando-se sempre de que estamos diante de um direito humano.

Destaca-se, finalmente, o quanto um maior conhecimento de experiências de países ibero-americanos, mesmo que com contornos políticos diferentes do brasileiro, pode auxiliar com o aproveitamento de experiências positivas, que já demonstram resultados numa melhor garantia do acesso à saúde e na sua efetivação como direito de todos.

\section{Referências}

AITH, F. Curso de direito sanitário: a proteção da saúde no Brasil. São Paulo: Quartier Latin, 2007.

AITH, F.; DALLARI, S. Vigilância em saúde no Brasil: os desafios dos riscos sanitários do século XXI e a necessidade de criação de um sistema nacional de vigilância em saúde. Revista de Direito Sanitário, São Paulo, v. 10, n. 2, p. 94-125, ago./nov. 2009. Disponível em: <http://www.revistas. usp.br/rdisan/article/view/13165>. http://dx.doi.org/10.11606/issn.2316-9044.v10i2p94-125.

AVRITZER, L. Sociedade civil, instituições participativas e representação: da autorização à legitimidade da ação. DADOS, v. 50, n. 3, p. 443-464, 2007. Disponível em: <http://www. scielo.br/pdf/dados/v50n3/01.pdf>. http://dx.doi.org/10.1590/S0011-52582007000300001.

\footnotetext{
${ }^{5}$ AVRITZER, L. Sociedade civil, instituições participativas e representação: da autorização à legitimidade da ação. DADOS, v. 50, n. 3, p. 443-464, 2007. Disponível em: <http://www.scielo.br/pdf/dados/v50n3/01. pdf>. http://dx.doi.org/10.1590/S0011-52582007000300001.

${ }^{6}$ LAVALLE, A.; HOUTZAGER, P.; CASTELLO, G. Democracia, pluralização da representação e sociedade civil. Lua Nova, v. 67, p. 49-103, 2006. Disponível em: <http://www.scielo.br/pdf/ln/n67/a04n67.pdf>. http://dx.doi.org/10.1590/S0102-64452006000200004.

${ }^{7}$ DALLARI, S.; NUNES JR., V. Direito sanitário. São Paulo: Verbatim, 2010.
} 
DALlARI, S. Uma nova disciplina: o direito sanitário. Rev. Saúde Públ., v. 22, n. 2, p. 327-334, 1988. Disponível em: <http://www.scielo.br/pdf/rsp/v22n4/08.pdf>. http://dx.doi.org/10.1590/S0034-89101988000400008.

DALLARI, S.; NUNES JR., V. Direito sanitário. São Paulo: Verbatim, 2010.

LAVALLE, A.; HOUTZAGER, P.; CASTELLO, G. Democracia, pluralização da representação e sociedade civil. Lua Nova, v. 67, p. 49-103, 2006. Disponível em: <http://www.scielo.br/pdf/ $\ln /$ 667/a04n67.pdf>. http://dx.doi.org/10.1590/S0102-64452006000200004.

SCHEFFER, M. Coberturas assistenciais negadas pelos planos e seguros de saúde em ações julgadas pelo Tribunal de Justiça do Estado de São Paulo. Revista de Direito Sanitário, São Paulo, v. 14, n. 1, p. 122-132, mar./jun. 2013. Disponível em: <http://www.revistas.usp. br/rdisan/article/view/56627>. http://dx.doi.org/10.11606/issn.2316-9044.v14i1p122-131.

Marcelo Dayrell Vivas -Especialista em Direitos Humanos, Universidade Católica de Brasília; especialista em Democracia Participativa e Movimentos Sociais, Universidade Federal de Minas Gerais; especialista em Dependência Química, Universidade de São Paulo. Defensor Público. Membro da Comissão de Estudos Interdisciplinares da Defensoria Pública Geral de São Paulo. São Paulo/SP, Brasil.E-mail: marcelodayrell@gmail.com. 